\title{
PERANCANGAN ULANG ALAT PENGERING BIJI KAKAO TIPE ROTARI SEDERHANA PADA USAHA MANDIRI DI DESA WIYONO KABUPATEN PESAWARAN
}

\author{
Ahmad Yudi Eka Risano1, Novri Tanti ${ }^{2}$, Maulana Efendi ${ }^{3}$ \\ Jurusan Teknik Mesin Universitas Lampung ${ }^{1,2,3}$ \\ Jl. Prof. Dr. Soemantri Brojonegoro No.1 Bandar Lampung \\ Email : yudi_95@yahoo.com¹,novritanti123@yahoo.com², maulanaefendi123@yahoo.com³
}

\begin{abstract}
ABSTRAK
Penelitian ini dilakukan pada alat pengering biji kakao untuk proses pengeringan biji kakao milik Usaha Mandiri di Desa Wiyono, Kabupaten Pesawaran. Penelitian ini bertujuan untuk merancang ulang alat pengering biji kakao tipe rotari sederhana agar proses pengeringan lebih efektif dan didapat kualitas hasil pengeringan biji kakao lebih baik. Perhitungan yang dilakukan meliputi dimensi alat pengering, termal yang terjadi pada alat pengering, dan kebutuhan bahan bakar pada alat pengering biji kakao tipe rotari sederhana, serta dilakukan simulasi pada model alat pengering biji kakao tipe rotari sederhana yang telah dirancang menggunakan Software Autodesk CFD untuk mengetahui sebaran suhu pada model alat pengering yang telah dirancang. Dari hasil penelitian yang telah dilakukan alat pengering biji kakao tipe rotari sederhana ini memiliki dimensi ruang pengering dengan diameter $90 \mathrm{~cm}$, panjang $108 \mathrm{~cm}$, dan tebal $1,2 \mathrm{~mm}$. sebaran suhu pada ruang pengering sebesar $65,06^{\circ} \mathrm{C}$, kalor yang dibutuhkan untuk proses pengeringan biji kakao sebesar 1028906,047 KJ, waktu yang dibutuhkan untuk proses pengeringan \pm 8 jam 14 menit dan bahan bakar yang dibutuhkan untuk proses pengeringan sebanyak 302,62 kg atau 0,30260 kubik serta sebaran suhu rata-rata hasil simulasi menggunkan Software Autodesk CFD sebesar $63,5116^{\circ} \mathrm{C}$.
\end{abstract}

Kata Kunci: kakao, pengeringan, Autodesk CFD, suhu.

\section{PENDAHULUAN}

Pengeringan kakao yang dilakukan pada usaha mandiri di Desa Wiyono ada dua cara yaitu; pertama biji kakao yang telah dikeluarkan dari buahnya dijemur sehari penuh dibawah sinar matahari (tanpa mendung) kemudian dilanjutkan dengan menggunakan oven atau alat pengering agar kadar air dalam biji kako mencapai standar yang ada. Kedua biji kakao langsung dikeringkan pada oven atau alat pengering yang ada hingga kadar air mencapai standar yang ada. Kedua cara ini kurang efisien karena suhu yang dihasilkan cukup tinggi sehingga mutu dari biji kakao yang telah dikeringkan kurang baik [1].

Penelitian ini bertujuan merancang ulang alat pengering biji kakao tipe rotari sesuai kebutuhan agar didapat hasil pengeringan yang lebih baik dan menghitung perpindahan panas yang terjadi pada alat pengering biji kakao tipe rotari sederhana yang dirancang, serta mensimulasikan alat pengering biji kakao tipe rotari sederhana yang telah dirancang dengan menggunakan Software Autodesk $C F D$.

\section{METODE PENELITIAN}

Penelitian ini dilakukan dengan melalui beberapa tahapan, yaitu:

\section{a. Pengumpulan data yang diperlukan}

Pengumpulan data-data pendukung analisis berupa data teknis, properties, dan geometris dari alat pengering kakao yang ada di desa Wiyono, kabupaten Pesawaran.

\section{b. Perhitungan dimensi dan thermal alat pengering kakao}


Perhitungan ini dilakukan untuk menentukan dimensi alat pengering kakao dan besarnya laju perpindahan panas yang terjadi secara manual.

\section{c. Pemodelan alat pengering}

Pada tahap ini dilakukan pembuatan gambar rancangan dari alat pengering kakao menggunakan software Inventor.

\section{d. Analisis}

Pada tahap ini dilakukan analisis menggunakan software Autodesk simulation $C F D$ untuk mengetahui apakah sebaran suhu telah merata.

\section{e. Pengolahan data}

Pengolahan data dilakukan dengan menganalisis data distribusi temperatur, dan perpindahan panas berdasarkan hasil pemodelan.

\section{HASIL DAN PEMBAHASAN}

\section{Data Hasil Pengukuran}

Adapun data hasil pengukuran ini dibagi menjadi dua yaitu sebagai berikut ;

1. Spesifikasi alat pengering biji kakao

Adapun spesifikasi alat pengering biji kakao yang ada di desa Wiyono, kabupaten Pesawaran adalah seperti yang dijelaskan pada tabel 1 di bawah ini ;

Tabel 1. Spesifikasi alat pengering konvensional

\begin{tabular}{|l|c|}
\hline \multicolumn{1}{|c|}{ Uraian } & Ukuran \\
\hline Panjang alat & $240 \mathrm{~cm}$ \\
\hline Lebar alat & $120 \mathrm{~cm}$ \\
\hline Tinggi alat & $73 \mathrm{~cm}$ \\
\hline Waktu pengeringan & \pm 16 jam \\
\hline $\begin{array}{l}\text { Kebutuhan bahan } \\
\text { bakar }\end{array}$ & 1 kubik \\
\hline
\end{tabular}

2. Sebaran suhu pada alat pengering biji kakao

Adapun sebaran suhu ruang pengering yang ada pada alat pengering biji kakao di desa Wiyono, kabupaten Pesawaran diambil pada sembilan titik seperti yang dijelaskan pada gambar 1 dibawah ini ;

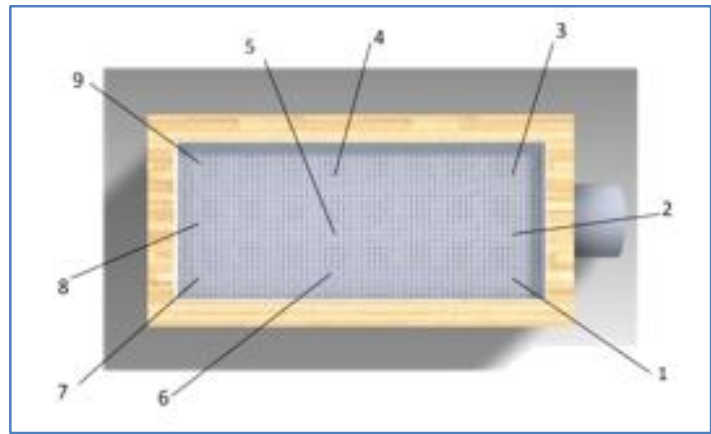

Gambar 1. Sebaran suhu pada alat pengering

Sedangkan besarnya suhu yang tersebar di ruang pengering pada alat pengering konvensional ini dapat dilihat pada tabel 2 di bawah ini;

Tabel 2 Sebaran suhu ruang pengering pada alat pengering konvensional

\begin{tabular}{|c|c|}
\hline Nomor & Suhu $\left({ }^{\mathbf{}} \mathbf{C}\right)$ \\
\hline 1 & 111,3 \\
\hline 2 & 110,7 \\
\hline 3 & 129,3 \\
\hline 4 & 129,2 \\
\hline 5 & 108,6 \\
\hline 6 & 104,4 \\
\hline 7 & 109,6 \\
\hline 8 & 108,4 \\
\hline 9 & 120,3 \\
\hline Rata-rata & 114,64 \\
\hline
\end{tabular}

3. Dimensi Alat Pengering Biji Kakao

Tipe Rotari Sederhana

Adapun yang dimaksud dimensi alat pengering adalah dimensi dari ruang pengering berbentuk silinder. Dimensi ruang pengering dari alat pengering biji kakao tipe rotari sderhana dapat dihitung menggunakan data sebagai berikut;

Kapasitas $\quad: 200 \mathrm{~kg}$

Percepatan Grafitasi $: 9,81 \mathrm{~m} / \mathrm{s}^{2}$

Diameter $\quad: 90 \mathrm{~cm}$

Volume kakao yang diinginkan $20 \%$ volume total

Tekanan : $1 \mathrm{~atm}$

Massa Jenis Kakao $: 1,467 \times 10^{-3} \mathrm{~kg} / \mathrm{cm}^{3}$ [2]

Tegangan Yield stainless steel $\left(\sigma_{\mathrm{y}}\right): 42,2$ Mpa 
Selanjutnya dengan menggunakan data di atas panjang dan tebal silinder dapat dihitung sebagai berikut;

\section{1) Panjang}

Mula-mula dihitung volume kakao dengan kapasitas 200 kg sebagai berkut [3];

$$
\begin{aligned}
\mathrm{V}_{\text {kakao }} & =\frac{m_{\text {kakao }}}{\rho_{\text {kakao }}} \\
& =\frac{200}{1,467 \times 10^{-3}} \\
& =136332,65 \mathrm{~cm}^{3}
\end{aligned}
$$

Karena volume kakao yang kita inginkan adalah sebesar $20 \%$ volume total, maka volume total dapet dihitung sebagai berikut;

$$
\begin{aligned}
\mathrm{V}_{\text {total }} & =\mathrm{V}_{\text {kakao }} \times 5 \\
& =136332,65 \mathrm{~cm}^{3} \times 5 \\
& =681663,25 \mathrm{~cm}^{3}
\end{aligned}
$$

Menghitung luas penampang tabung silinder sebagai berikut ;

$$
\begin{aligned}
& \text { Luas penampang }=\pi \mathrm{r}^{2} \\
& =\pi(45)^{2} \\
& =6361,72 \mathrm{~cm}^{2}
\end{aligned}
$$

Selanjutnya dengan membagi volume total dengan luas penampang didapat panjang silinder sebagai berikut ;

$$
\begin{aligned}
\mathrm{L} & =\frac{V_{\text {total }}}{\text { Luas penampang }} \\
& =\frac{681663,25}{6361,72} \\
& =107,15 \mathrm{~cm} \approx 108 \mathrm{~cm}
\end{aligned}
$$

2) Tebal silinder

Mula-mula dihitung luas selimut silinder sebesar $20 \%$ sebagai berikut ;

$$
\begin{aligned}
\text { A }_{\text {selimut }} & 20 \%=20 \%(2 \pi \mathrm{rL}) \\
& =20 \%(2 \times \pi \times(45) \times(108)) \\
& =30536,28 \mathrm{~cm}^{2}
\end{aligned}
$$

Selanjutnya dihitung gaya akibat massa kakao 200 kg sebagai berikut;

$$
\begin{aligned}
\mathrm{F} & =\mathrm{m} \cdot \mathrm{g} \\
& =200 \times 9,81 \\
& =1962 \mathrm{~N}
\end{aligned}
$$

Karena gaya akibat massa kakao dianggap terdistribusi merata, maka tekanan yang dihasilkan oleh massa kakao dapat dihitung sebagai berikut ;

$$
\begin{aligned}
P_{\text {kakao }} & =\frac{F}{A} \\
& =\frac{1962}{30536,28} \\
& =0,06425 \mathrm{~N} / \mathrm{cm}^{2} \\
& =0,0006425 \mathrm{Mpa}
\end{aligned}
$$

Selanjutnya dengan menjumlahkan tekanan akibat kakao ( $\left.\mathrm{P}_{\text {kakao}}\right)$ dengan tekanan akibat termal $\left(\mathrm{P}_{\text {termal }}\right)$, maka di dapat $\mathrm{P}_{\text {total }}$ sebagai berikut ;

$$
\begin{aligned}
\mathrm{P}_{\text {total }}= & \mathrm{P}_{\text {kakao }}+\mathrm{P}_{\text {termal }} \\
= & 0,0006425 \mathrm{Mpa}+0,101325 \mathrm{Mpa} \\
& =0,1019675 \mathrm{Mpa}
\end{aligned}
$$

Selanjutnya tebal silinder dapat dihitung sebagai berikut ;

$$
\begin{aligned}
\sigma_{\mathrm{y}} & =\frac{P_{\text {total }} D}{2 t} \\
\mathrm{t}=\frac{P_{\text {total }} D}{2 \sigma_{y}} & \\
& =\frac{(0,1019675)(900)}{2(42,2)} \\
& =1,087 \mathrm{~mm} \approx 1,2 \mathrm{~mm}
\end{aligned}
$$

4. Kebutuhan energi pada proses pengeringan

Adapun energi yang dibutuhkan selama proses pengeringan pada alat pengering biji kakao tipe rotari sederhana ini dapat dihitung menggunakan data sebagai berikut [4],[5],[6];

Berat total kakao awal $\left(\mathrm{W}_{\mathrm{kb}}\right): 200 \mathrm{~kg}$

Berat total kakao dengan

Kadar air 0\% ( $\left.\mathrm{W}_{\mathrm{ko}}\right)$ : $60 \mathrm{~kg}$

Berat air total kakao dengan

Kadar air 7\% $\left(\mathrm{W}_{\mathrm{kk}}\right) \quad: 64,51 \mathrm{~kg}$

Berat air total kakao $\left(\mathrm{W}_{\mathrm{i}}\right) \quad: 140 \mathrm{~kg}$

Berat air yang diuapkan $\left(\mathrm{W}_{\mathrm{r}}\right): 135,49 \mathrm{~kg}$

Temperatur awal kakao $: 30^{\circ} \mathrm{C}$

Temperatur masuk

pengeringan $\left(\mathrm{T}_{\mathrm{s}}\right) \quad: 175^{\circ} \mathrm{C}$

Temperatur pengeringan $\left(\mathrm{T}_{\mathrm{d}}\right): 65,1155^{\circ} \mathrm{C}$

Panas jenis kakao (C $\left.\mathrm{C}_{\text {kakao }}\right): 2,225176 \mathrm{kj} / \mathrm{kg}$

Panas laten penguapan air $\left(\mathrm{h}_{\mathrm{fg}}\right)$

$2345,11356 \mathrm{kj} / \mathrm{kg}$ 
Nilai kalor bakar kayu bakar

(LHVkayubakar)

$: 17000 \mathrm{~kJ} / \mathrm{kg}$

Panjang alat

: $108 \mathrm{~cm}$

Diameter silinder

: $90 \mathrm{~cm}$

5. Energi pemanasan kakao

$$
\begin{aligned}
\mathrm{Q}_{\mathrm{t}}= & \mathrm{W}_{\mathrm{kb}} \times \mathrm{C}_{\text {pkakao }} \times\left(\mathrm{T}_{\mathrm{d}}-\mathrm{T}_{\mathrm{a}}\right) \\
& =(200 \mathrm{~kg}) \times\left(2,255176 \mathrm{Kj} / \mathrm{kg}^{0} \mathrm{C}\right) \mathrm{x} \\
& \left(65,06^{\circ} \mathrm{C}-30^{\circ} \mathrm{C}\right) \\
& =15813,29411 \mathrm{KJ}
\end{aligned}
$$

6. Energi pemanasan air kakao

$$
\begin{aligned}
& \mathrm{Q}_{\mathrm{w}}= \mathrm{W}_{\mathrm{i}} \times \mathrm{C}_{\text {pair }} \times\left(\mathrm{T}_{\mathrm{d}}-\mathrm{T}_{\mathrm{a}}\right) \\
&=(140 \mathrm{~kg}) \times\left(4,18 \mathrm{KJ} / \mathrm{kg}^{\circ} \mathrm{C}\right) \times \\
& \\
& \quad\left(65,06^{\circ} \mathrm{C}-30^{\circ} \mathrm{C}\right) \\
&=20517,112 \mathrm{KJ}
\end{aligned}
$$

7. Energi penguapan air kakao

$$
\begin{aligned}
\mathrm{Q}_{\mathrm{l}} & =\mathrm{W}_{\mathrm{r}} \times \mathrm{h}_{\mathrm{fg}} \\
& =135,49 \mathrm{~kg} \times 2345,2512 \mathrm{KJ} / \mathrm{kg} \\
& =317758,0851 \mathrm{KJ}
\end{aligned}
$$

8. Laju aliran energi koveksi

$$
\begin{aligned}
\dot{Q}_{k v} & =\mathrm{h} \mathrm{A} \Delta \mathrm{T} \\
& =(109,2650209) \times(0,972) \mathrm{x} \\
(175 & -65,06) \\
& =11676,47732 \mathrm{~W} \\
& =42034,47732 \mathrm{KJ} / \mathrm{Jam}
\end{aligned}
$$

9. Waktu yang dibutuhkan selama proses pengeringan

$$
\begin{aligned}
\mathrm{N} & =\frac{Q_{t}+Q_{w}+Q_{l}}{\dot{Q}_{k v}} \\
& =\frac{15813,29411+20517,112+317758,0851}{42034,47732} \\
& =8,24 \mathrm{Jam} \text { atau 8 Jam 14 Menit }
\end{aligned}
$$

Pada alat pengering yang ada di desa Wiyono, kabupaten Pesawaran proses pengeringan melalui dua tahap yaitu pertama, dijemur pada terik matahari selama kurang lebih 10-12 jam tanpa mendung. Kedua, dilanjutkan dengan mengeringkan biji kakao yang telah dijemur seharian dibawah sinar matahari menggunakan alat penering yang ada di desa Wiyono, kabupaten Pesawaran kurang lebih selama 3-4 jam. Sehingga total waktu yang diperlukan oleh pengering biji kakao yang ada di desa Wiyono, kabupaten Pesawaran kurang lebih 16 jam, sedangkan jika menggunakan alat pengering kakao tipe rotari sederhana biji kakao yang baru dikeluarkan dari buah langsung dimasukkan dan dikeringkan pada ruang pengering selama kurang lebih 8 jam

10. Kebutuhan kayu bakar selama proses pengeringan

Kebutuhan kayu bakar dihitung dengan membagi total kalor yang dibutuhkan untuk satu siklus pengeringan dengan nilai kalor kayu bakar sebagai berikut;

$$
\begin{aligned}
& \text { m}_{\text {Kayu Bakar }}=\frac{Q_{\text {total }}}{\text { LHV Kayu Bakar }} \\
& =\frac{\mathrm{Q}_{\mathrm{t}}+\mathrm{Q}_{\mathrm{W}}+\mathrm{Q}_{\mathrm{l}}+\mathrm{Q}_{\mathrm{kv}}+\mathrm{Q}_{\mathrm{lw}}+\mathrm{Q}_{\mathrm{lv}}}{L H V \text { Kayu Bakar }} \\
& =\frac{1028906,047 \mathrm{KJ}}{17.000 \mathrm{KJ} / \mathrm{Kg}} \\
& =60,524 \mathrm{~kg}
\end{aligned}
$$

Menurut Yunianto (2014), efisiensi ruang bakar tradional menggunakan dinding beton adalah $20 \%$ [7], sehingga massa total kayu yang dibutuhkan selama proses pengeringan biji kakao adalah ;

Total Kayu Bakar $=\frac{60,524 \mathrm{~kg}}{0,2}$

$$
=302,62 \mathrm{~kg}(0,30260 \text { kubik })
$$

\section{Sebaran suhu alat pengering biji kakao}

Simulasi yang dilakukan menggunakan software autodesk CFD [8]. Adapun tujuan dari dilakukannya simulasi ini adalah untuk mengetahui sebaran suhu yang terjadi pada alat pengering biji kakao tipe rotari sederhana yang telah dirancang. Hasil simulasi dibagi menjadi enam berdasarkan model pipa yang digunakan untuk mencapai temperatur optimal pengeringan biji kakao yaitu sebagai berikut; 
1) Desain awal

Adapun desain awal dari alat pengering ini tanpa menggunakan pipa pada ruang pengering seperti yang diperlihatkan pada gambar 2 berikut;

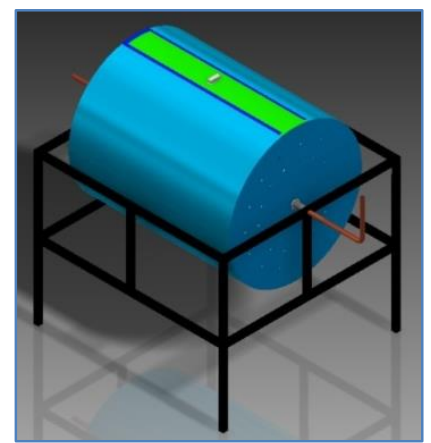

Gambar 2. Desain awal

Hasil simulasi dari desain awal alat pengering rotari sederhana ini seperti yang diperlihatkan pada gambar 3 dibawah ini;

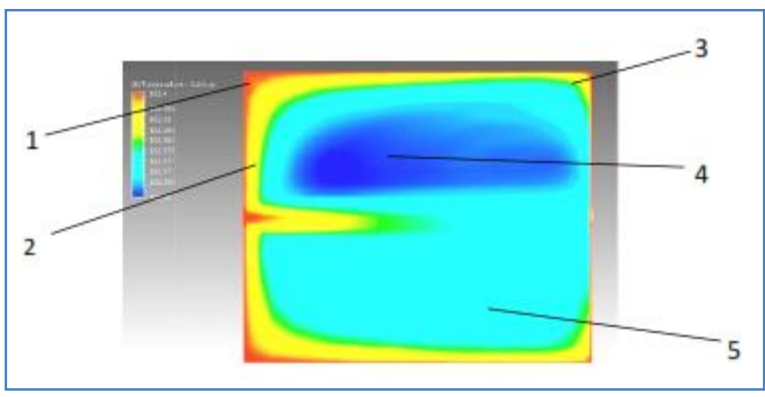

Gambar 3 Hasil simulasi desain awal

Sebaran suhu rata-rata pada ruang pengering desain awal ini cukup tinggi jika dibandingkan suhu rata-rata pengeringan biji kakao yaitu sebesar $65^{\circ} \mathrm{C}$. adapun sebaran suhu rata-rata pada ruang pengering diperlihatkan pada tabel 3 berikut;

Tabel 3. Sebaran suhu pada desain awal

\begin{tabular}{|c|l|}
\hline Nomor & \multicolumn{1}{|c|}{ Suhu $\left({ }^{\circ} \mathbf{C}\right)$} \\
\hline 1 & 102,6 \\
\hline 2 & 102,588 \\
\hline 3 & 102,582 \\
\hline 4 & 102,56 \\
\hline 5 & 102,574 \\
\hline
\end{tabular}

2) Model pipa pertama

Desain awal pengering rotari sederhana ini memiliki suhu rata-rata terlalu tinggi sehingga dilakukan pengoptimalan pada desain alat pengering dengan menambahkan pipa tembaga pada ruang pengering. Adapun model pipa yang digunakan seperti yang diperlihatkan pada gambar .4 di bawah ini;

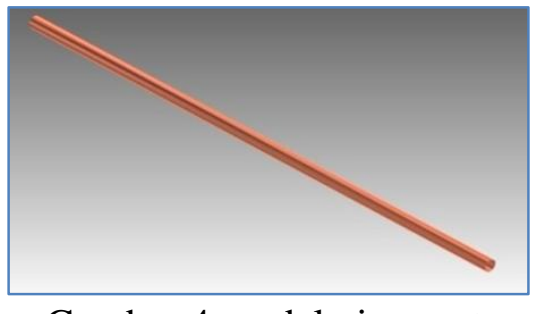

Gambar 4 model pipa pertama

Hasil simulasi menggunakan model pipa pertama diperlihatkan pada gambar 5 di bawah ini;

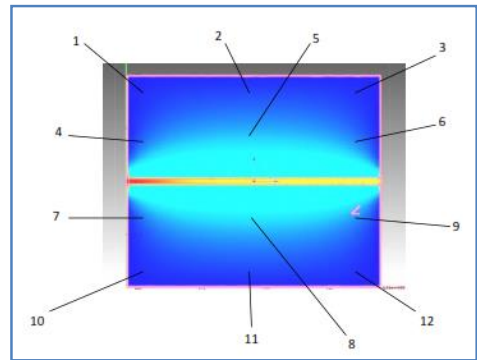

Gambar 5. Hasil simulasi model pipa pertama

Sebaran suhu pada ruang menggunakan model pipa pertama diperlihatkan pada tabel 4 berikut ini;

Tabel 4. Sebaran suhu model pipa pertama

\begin{tabular}{|c|c|}
\hline Nomor & Suhu $\left({ }^{\mathbf{}} \mathbf{C}\right)$ \\
\hline 1 & 34,83 \\
\hline 2 & 36,78 \\
\hline 3 & 35,16 \\
\hline 4 & 40,80 \\
\hline 5 & 53.01 \\
\hline 6 & 43,99 \\
\hline 7 & 41,16 \\
\hline 8 & 50,47 \\
\hline 9 & 45,51 \\
\hline 10 & 34,76 \\
\hline 11 & 36,66 \\
\hline 12 & 35,20 \\
\hline Rata-rata & $\mathbf{4 0 , 6 9}$ \\
\hline
\end{tabular}

Tabel 4 menjelaskan rata-rata sebaran suhu pada ruang pengering sebesar $40,69^{\circ} \mathrm{C}$, suhu ini cukup kecil 
dibandingkan dengan suhu pengeringan biji kakao yaitu sebesar $65^{\circ} \mathrm{C}$.

3) Model pipa kedua

Suhu rata-rata ruang pengering dari model pipa pertama terlalu kecil dibandingkan suhu optimal pengeringan biji kakao, oleh sebab itu digunakan model pipa kedua sepert yang diperlihatkan pada gambar 6 dibawah ini;

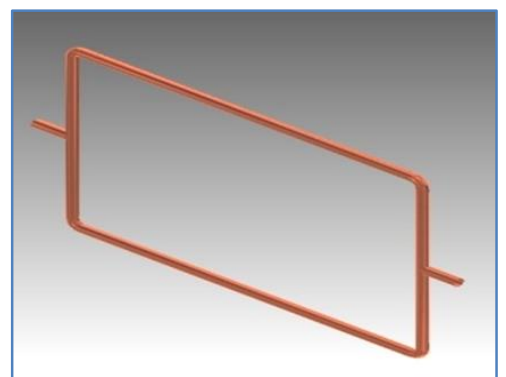

Gambar 6. Model pipa kedua

Hasil simulasi menggunakan pipa kedua diperlihatkan pada gambar 7 di bawah ini;

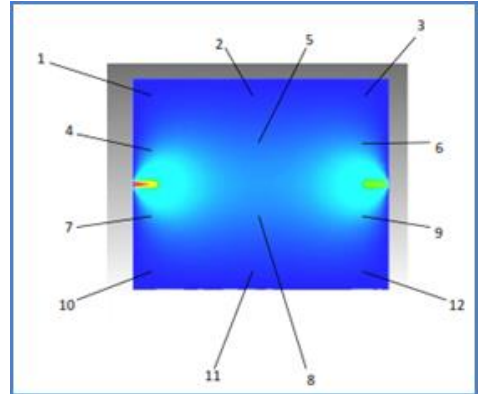

Gambar 7. Hasil simulasi model pipa kedua

Sebaran suhu pada ruang pengering menggunakan model pipa kedua seperti yang diperlihatkan tabel 5 berikut;

Tabel 5. Sebaran suhu dengan model pipa kedua

\begin{tabular}{|c|c|}
\hline Nomor & Suhu $\left({ }^{\circ} \mathbf{C}\right)$ \\
\hline 1 & 30,52 \\
\hline 2 & 30,89 \\
\hline 3 & 30,61 \\
\hline 4 & 41,39 \\
\hline 5 & 39,19 \\
\hline 6 & 43,77 \\
\hline 7 & 44,89 \\
\hline 8 & 40,32 \\
\hline 9 & 49,76 \\
\hline 10 & 31,16 \\
\hline 11 & 31,98 \\
\hline 12 & 31,82 \\
\hline Rata-rata & $\mathbf{3 7 , 1 9}$ \\
\hline
\end{tabular}

Pada tabel 5 terlihat bahwa suhu rata-rata hasil simulasi pada ruang pengering rotari sederhana sebesar $37,19^{\circ} \mathrm{C}$. suhu rata-rata hasil simulasi menggunakan model pipa kedua belum mencapai suhu optimal pengeringan biji kakao yaitu sebesar $65^{\circ} \mathrm{C}$.

4) Model pipa ketiga

Sebaran suhu rata-rata pada ruang pengering menggunakan model pipa kedua belum mencapai suhu optimal pengeringan biji kakao, oleh sebab itu kembali dilakukan optimalisasi dengan menggunakan model pipa ketiga seperti yang diperlihatkan pada gambar 8 di bawah ini;

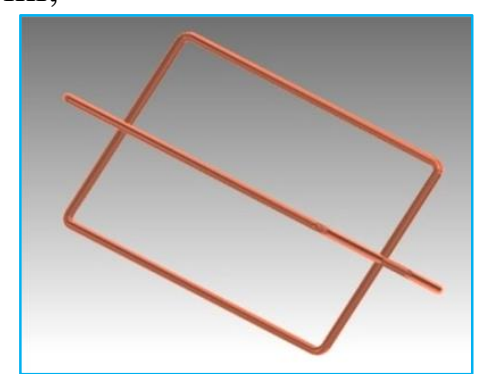

Gambar 8. Model pipa ketiga

Hasil simulasi menggunakan model pipa ketiga diperlihatkan pada gambar 9 dibawah ini;

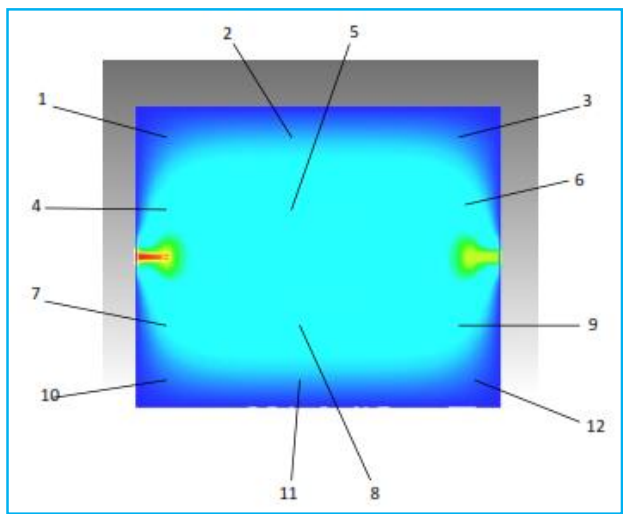

Gambar 9. Hasil simulasi model pipa ketiga

Sebaran suhu hasil simulasi menggunakan model pipa ketiga diperlihatkan pada tabel 6 di bawah ini; 
Tabel 6 Sebaran suhu menggunakan model pipa ketiga

\begin{tabular}{|c|c|}
\hline Nomor & Suhu $\left({ }^{\circ} \mathbf{C}\right)$ \\
\hline 1 & 39,63 \\
\hline 2 & 42,39 \\
\hline 3 & 41,75 \\
\hline 4 & 67,66 \\
\hline 5 & 70,49 \\
\hline 6 & 67,40 \\
\hline 7 & 67,90 \\
\hline 8 & 70,00 \\
\hline 9 & 73,14 \\
\hline 10 & 40,19 \\
\hline 11 & 47,26 \\
\hline 12 & 39,31 \\
\hline Rata-rata & $\mathbf{5 5 , 5 9}$ \\
\hline
\end{tabular}

Pada tebel 6 memperlihatkan suhu rata-rata hasil simulasi menggunakan model pipa ketiga sebesar $55,59^{\circ} \mathrm{C}$.

5) Model pipa keempat

Pada model pipa ketiga menperlihatkan bahwa sebaran suhu ratarata pada ruang pengering belum mencapai suhu optimal pengeringan biji kakao. Oleh sebab itu dilakukan kembali optimalisasi dengan memodifikasi model pipa yang digunakan. Adapun model pipa keempat yang digunakan seperti yang diperlihatkan pada gambar 10 dibawah ini;

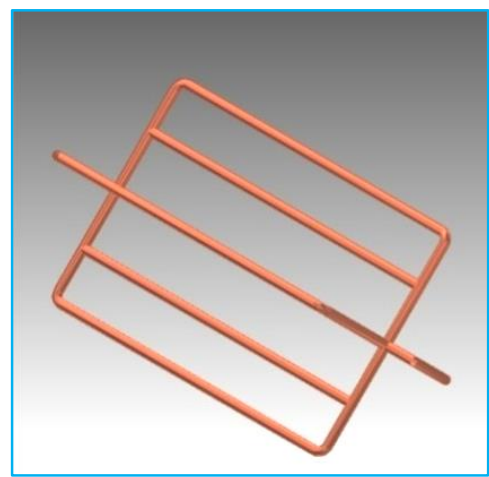

Gambar 10. Model pipa keempat

Hasil simulasi menggunakan model pipa keempat diperlihat pada gambar 11 dibawah ini;

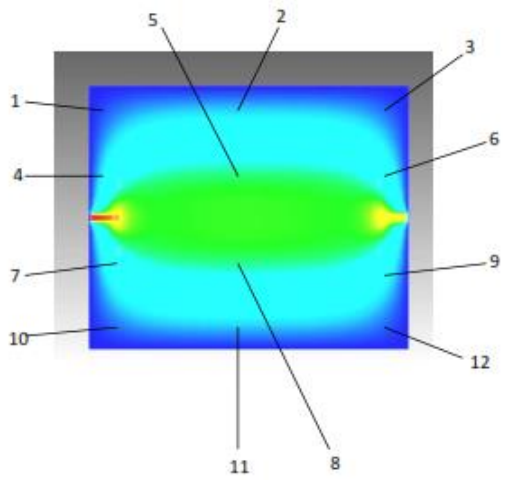

Gambar 11. Hasil simulasi model pipa keempat

Sebaran suhu hasil simulasi menggunaan model pipa keempat diperlihat pada tabel 7 di bawah ini;

Tabel 7 Sebaran suhu model pipa keempat

\begin{tabular}{|c|c|}
\hline Nomor & Suhu $\left({ }^{\circ} \mathbf{C}\right)$ \\
\hline 1 & 35,17 \\
\hline 2 & 46,53 \\
\hline 3 & 41,66 \\
\hline 4 & 55,89 \\
\hline 5 & 96,64 \\
\hline 6 & 71,99 \\
\hline 7 & 72,08 \\
\hline 8 & 97,99 \\
\hline 9 & 70,47 \\
\hline 10 & 36,61 \\
\hline 11 & 51,84 \\
\hline 12 & 35,56 \\
\hline Rata-rata & $\mathbf{5 9 , 3 7}$ \\
\hline
\end{tabular}

Pada tabel 7 memperlihatkan suhu rata-rata pada ruang pengering sebesar $59,37^{\circ} \mathrm{C}$.

6) Model pipa kelima

Pada model pipa keempat menperlihatkan bahwa sebaran suhu ratarata pada ruang pengering belum mencapai suhu optimal pengeringan biji kakao. Oleh sebab itu dilakukan kembali optimalisasi dengan memodifikasi model pipa yang digunakan. Adapun model pipa kelima yang digunakan seperti yang diperlihatkan pada gambar 12. 


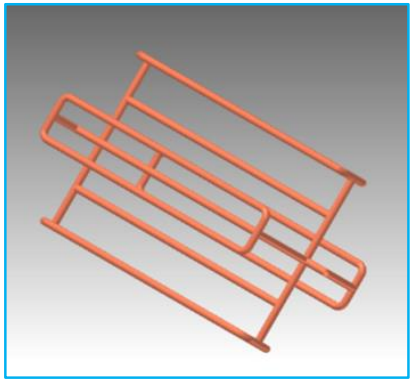

Gambar 12. Model pipa tembaga kelima

Hasil simulasi menggunakan model pipa keempat diperlihat pada gambar 13 berikut:

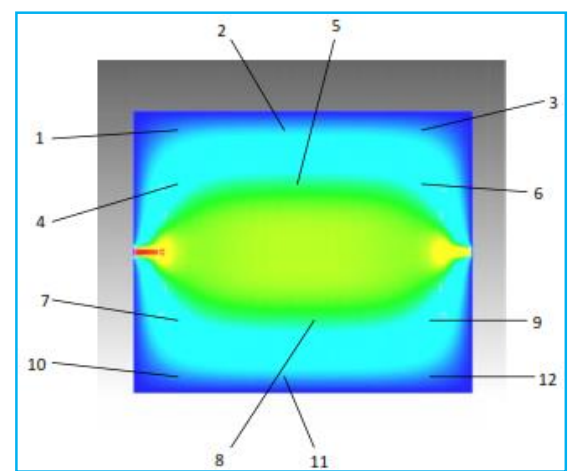

Gambar 13 Hasil simulasi dengan model pipa kelima

Sebaran suhu hasil simulasi menggunaan model pipa keempat diperlihat pada tabel 8 .

Tabel 8. Sebaran suhu model pipa kelima

\begin{tabular}{|c|c|}
\hline Nomor & Suhu $\left.\mathbf{~}^{\mathbf{}} \mathbf{C}\right)$ \\
\hline 1 & 40,13 \\
\hline 2 & 41,37 \\
\hline 3 & 40,48 \\
\hline 4 & 83,01 \\
\hline 5 & 92,76 \\
\hline 6 & 82,66 \\
\hline 7 & 81,47 \\
\hline 8 & 96,55 \\
\hline 9 & 82,34 \\
\hline 10 & 40,62 \\
\hline 11 & 41,17 \\
\hline 12 & 40,57 \\
\hline Rata-rata & $\mathbf{6 3 , 5 1}$ \\
\hline
\end{tabular}

Pada tabel 8 memperlihatkan suhu rata-rata pada ruang pengering sebesar $63,5116^{\circ} \mathrm{C}$. Sebaran suhu rata-rata pada ruang pengering dengan model pipa kelima telah mendekati suhu optimal pengeringan biji kakao. Model pipa kelima dipilih untuk digunakan pada alat pengering biji kakao tipe rotari sederhana karena sebaran suhu rata-rata pada ruang pengering telah mendekati suhu optimal pengeringan biji kakao.

\section{KESIMPULAN DAN SARAN}

\section{Kesimpulan}

Adapun kesimpulan yang bisa diambil dari penelitian ini sebagai berikut ;

1) Alat pengering biji kakao tipe rotari sederhana dengan kapasitas $200 \mathrm{~kg}$ memiliki ukuran panjang $128 \mathrm{~cm}$, lebar $120 \mathrm{~cm}$ dan tinggi $135 \mathrm{~cm}$ serta memiliki dimensi ruang pengering dengan panjang $108 \mathrm{~cm}$, diameter 90 $\mathrm{cm}$ dan tebal silinder $1,2 \mathrm{~mm}$. Sedangkan alat pengering kakao yang ada pada usaha mandiri di Desa Wiyono, Kabupaten Pesawaran memiliki ukuran panjang $240 \mathrm{~cm}$, lebar $120 \mathrm{~cm}$, dan tinggi $73 \mathrm{~cm}$.

2) Pada alat pengering biji kakao tipe rotari sederhana, pengeringan terjadi pada suhu sebesar $65,06^{\circ} \mathrm{C}$. Laju perpindahan panas yang terjadi adalah sebesar 42.034,477 KJ/Jam, dengan total kebutuhan energi sebesar 1.028.906,047 KJ.

3) Pada alat pengering biji kakao tipe rotari sederhana hasil simulasi sebaran suhu pada ruang pengering cukup rata dimana suhu rata-rata adalah sebesar $63,5116^{\circ} \mathrm{C}$, sedangkan pada alat pengering biji kakao pada desa wiyono tidak merata dengan suhu rata-rata sebesar $114,64^{\circ} \mathrm{C}$.

4) Waktu yang dibutuhkan untuk mengeringkan biji kakao dengan kapasitas $200 \mathrm{~kg}$ pada satu siklus proses pengeringan menggunakan alat pengering biji kakao tipe rotari sederhana adalah kurang lebih 8 jam 14 menit. Sedangkan waktu yang dibutuhkan untuk mengeringkan biji kakao dengan kapasitas $200 \mathrm{~kg}$ pada satu siklus proses pengeringan menggunakan alat pengering yang ada 
di Desa Wiyono adalah kurang lebih 16 jam.

\section{Saran}

Perlu dilakukan analisis lebih lanjut mengenai konstruksi alat pengering biji kakao tipe rotari sederhana ini untuk mengetahui gaya-gaya yang bekerja pada alat pengering tersebut agar alat pengering biji kakao ini dapat digunakan secara aman, serta perlu dibuat benda nyata dari alat pengering biji kakao tipe rotari sederhana ini agar dapat dilakukan pengujian secara nyata dan dapat membantu pengusaha biji kakao untuk mendapatkan hasil yang lebih optimal pada setiap proses pengeringan biji kakao.

\section{DAFTAR PUSTAKA}

[1]. Sunanto, H. 1998. Coklat Budidaya, Pengolahan Hasil dan Aspek Ekonominya. Kanisius. Jakarta.

[2]. Azis, M.F. 1996. Upaya Peningkatan Biji Kakao Melalui Sentralisasi Pengolahan. Pusat Penelitian Kopi dan Kakao.

[3]. Statistik Perkebunan. 2014. Statistik Perkebunan Indonesia Komoditas Kakao. https://cocoainfo.wordpress.com /tag/statistik-perkebunankakao/. Diakses pada tanggal 8 Mei 2016 pukul 13.03 wib.

[4]. Holman, J.P. 1988. Perpindahan Kalor. Erlangga. Jakarta.

[5]. Incropera, Frank P dan De Witt, Davit P. 2007. Fundamental Of Heat And Mass Transfer Sixth Edition. Jhon Wiley \& Sons, Inc. Newyork.

[6]. Koestoer, Raldi Artono. 2002. Perpindahan Kalor. Salemba Teknika. Jakarta.

[7]. Yunianto, Bambang. Dkk. 2014. Pengembangan desan tungku bahan bakar kayu rendah polusi dengan menggunakan dinding beton semen. Jurusan teknik mesin, Universitas Diponegoro.

[8]. Taukia, Firman. 2008. Dasar-dasar CFD Menggunakan FLUENT. Informatika Bandung. Bandung. 